Article

\title{
Can We Predict the Winner in a Market with Network Effects? Competition in Cryptocurrency Market
}

\author{
Neil Gandal ${ }^{1,2}$ and Hanna Halaburda ${ }^{3,4, *,+}$ \\ Department of Economics, Tel Aviv University, Tel Aviv 6997801, Israel; gandal@post.tau.ac.il \\ 2 CEPR, London EC1V 0DX, UK \\ 3 Bank of Canada, Ottawa, ON K1A 0G9, Canada \\ 4 Stern School of Business, New York University, NY 10012, USA \\ * Correspondence: hhalaburda@gmail.com \\ + Views presented in this paper are those of authors, and do not represent Bank of Canada's position.
}

Academic Editors: Thomas D. Jeitschko and Mark J. Tremblay

Received: 18 March 2016 ; Accepted: 29 June 2016 ; Published: 7 July 2016

\begin{abstract}
We analyze how network effects affect competition in the nascent cryptocurrency market. We do so by examining early dynamics of exchange rates among different cryptocurrencies. While Bitcoin essentially dominates this market, our data suggest no evidence of a winner-take-all effect early in the market. Indeed, for a relatively long period, a few other cryptocurrencies competing with Bitcoin (the early industry leader) appreciated much more quickly than Bitcoin. The data in this period are consistent with the use of cryptocurrencies as financial assets (popularized by Bitcoin), and not consistent with winner-take-all dynamics. Toward the end of our sample, however, things change dramatically. Bitcoin appreciates against the USD, while other currencies depreciate against the USD. The data in this period are consistent with strong network effects and winner-take-all dynamics. This trend continues at the time of writing.
\end{abstract}

Keywords: network effects; cryptocurrencies; first mover advantage

\section{Introduction}

Even though it was introduced in 2009, the digital currency Bitcoin caught the interest of the mainstream media only in 2012. Due to its supposed anonymity, Bitcoin and other digital currencies are often compared to cash. However, unlike cash, these currencies are purely digital and used primarily online. While digital currencies are widely varied, the decentralized digital currencies that are based primarily on cryptography, called cryptocurrencies, have gotten most attention. Bitcoin is the most prominent of the cryptocurrencies.

The market of competing cryptocurrencies is an interesting market to analyze for several reasons. First, it was a brand new market, with many players entering and competing. It is also an excellent laboratory with well defined, and high quality data on prices and volumes over time.

Further, network effects are likely present in this market. Positive network effects arise when the value of a product or service increases with the number of users. From the network effects literature [1], in such environments we might expect a winner-take-all dynamics and convergence to one dominant player $^{1}$. Currencies in general provide one of the cleanest examples of network effects: The more popular a currency is, the more useful it is, and the easier it attracts new users. Therefore, one might

1 We discuss relevant literature more extensively in Sections 3 and 5. 
expect that the most popular cryptocurrency would grow even more popular, eventually dominating the whole market. We call this the reinforcement effect.

Currencies differ, however, in their attributes-and some of those that arrived later to the market may have higher quality. Several cryptocurrencies were developed to fix what their developers perceived as shortcomings of Bitcoin. Some of the changes may have attracted only a narrow group of users, while others may have had wider appeal as alternatives to Bitcoin. In particular, the relatively early competitors to Bitcoin, Litecoin and Peercoin, were developed to address major deficiencies of Bitcoin: namely, slow transaction times, a completely pre-determined number of coins in the Bitcoin system, as well as the incentive structure that promoted the use of very powerful specialized equipment to participate in the network ${ }^{2}$. Due to differences on several dimensions, Novacoin was considered by many to be better than Bitcoin, but it was introduced four years later. Availability of other, better or simply differentiated cryptocurrencies allows for a substitution effect. That is, the users could find it beneficial to substitute one cryptocurrency for another.

These two opposing forces have been also noticed in the industry, and were nicely summarized by Adam Levine, the Founder and Editor-in-Chief of the long running Let's Talk Bitcoin! show. In an article from 9 September 2013, entitled "The Opportunities of Alt-coins" [2], he wrote

[I used to believe that] there can only be one. The Network effect is simply too strong. Bitcoin has orders of magnitudes more adoption, acceptance and use compared to any other cryptocurrency on the market. The game is over and Bitcoin won.

Later, however, he noted that it was possible that a

substantially better product will almost always find its place in a market where the cost to move from one option to the other is cheap and easy. Cryptocurrency to Cryptocurrency (Bitcoin to Litecoin for example) transactions are frictionless; what exchange fees exist are minimal, transactions are fast, and no identity is required

As noted above, Novacoin could be considered to be of higher quality than Bitcoin, but it was introduced much later. Similar situations often occur in technology markets. Moreover, it is still not clear how markets in such situations develop. Especially, whether higher quality trumps the advantage of early presence and network effects ${ }^{3}$. The detailed data in the cryptocurrency market allows us to analyze this tradeoff. The finely delineated (daily) data makes an examination of this market particularly interesting, and enables us to gain insights into early dynamics of the market.

In this paper we analyze data on competing cryptocurrencies and ask whether the early dynamics could help us predict the outcome in this market. The ability to infer the future of the market from early dynamics would be very valuable for analyzing markets with network effects. What we find is "unfortunately not" - early dynamics do not indicate the eventual outcome in this market.

We began collecting data from this market in November 2013. To assess market expectations about the viability of each cryptocurrency we focus on prices of these cryptocurrencies. Prices (or changes in prices: returns) better reflect market participants' beliefs about the strength of network effects than other variables (e.g., the number of past transactions using a given cryptocurrency). Indeed, in an efficient market, prices and returns should account for any effects from other variables as well.

We find that, initially, neither the reinforcement nor the substitution effect dominated in the market. Later, as Bitcoin's price sharply increased beginning in October 2013, we see a clear substitution effect. The prices of other cryptocurrencies increase or fall together with Bitcoin's. Such dynamics are consistent with cryptocurrencies being purchased as financial assets rather than for usage as currency.

2 The rise of "elite mining" led to a more centralized network and created a potential danger to the stability of the system. We describe "mining" in more detail in Section 2.

3 For example, there is no agreement in the literature about the play of quality and network effect forces behind the competition between QWERY and Dvorak keyboard (See, e.g., [3,4]). 
We also find that the increase in the substitution effect is driven by the increased general interest in cryptocurrencies, as opposed to Bitcoin specifically.

In the last period of our sample, beginning at the end of April 2014, there is clear reinforcement effect favoring Bitcoin against all other cryptocurrencies. In particular, during this period, the price of Bitcoin increases in USD, while the prices of all other cryptocurrencies decline in USD. This suggests strong network effects and winner-take-all dynamics. Note that it is not that the increase in the price of Bitcoin indicates strong network effects, but rather that the stark movement of Bitcoin and the other currencies in opposite directions does ${ }^{4}$.

The strong network effects in favor of Bitcoin continued beyond the end of the period for which we have detailed data. Bitcoin remained at around $\$ 400$ from the end of April 2014 to the end of February 2016. In contrast, all of the other cryptocurrencies in our sample lost at least two-thirds of their value between April 2014 and February 2016. Peercoin, for example traded at \$2.21 on 30 April 2014, and had fallen to 46 cents by 29 February $2016^{5}$. So, in the overall sense, Bitcoin has "won-it-all" in this market.

The paper proceeds as follows: In Section 2, we provide a brief background on Cryptocurrencies. At the end of this section, we provide a brief description of "mining" which both controls the supply and verifies transactions. Section 3 discusses related literature. In Section 4 , we discuss the data we employ in the analysis; the analysis itself is in Section 5. Section 6 extends the analysis by employing "Google trends data". In Section 7 we conclude with some further discussion.

\section{Brief Background on Cryptocurrencies}

Bitcoin, the first cryptocurrency, came to existence in 2009. In the following years, other cryptocurrencies were introduced as well. Bitcoin and the other digital currencies considered here are decentralized systems, i.e., have no central authority to validate and settle transactions. They use only cryptography (and a clever incentive system) to control transactions, manage the supply, and to prevent fraud. Hence, they often are referred to as cryptocurrencies. Once confirmed, all transactions are stored digitally and recorded in a "blockchain", which can be thought of as an accounting system. Payments are validated by a decentralized network.

Bitcoin's algorithm provides an effective safeguard against "counterfeiting" of the currency. However, the eco-system is still vulnerable to theft. Users keep keys to their Bitcoins and make transactions with the help of wallets. Exchanges facilitate trade between Bitcoins and fiat currencies, and also allow for storing Bitcoins. Bitcoins can be stolen through wallets or exchanges. Up until this point, exchanges have been targeted more frequently than wallets. Many wallets are located on users' computers, while exchanges by their nature are on-line. This makes exchanges an easier target. It was revealed in February 2014 that $\$ 350$ million worth of Bitcoins were stolen from Mt.Gox, which led to the shut-down of the exchange [5].

The supply of most cryptocurrencies increases at a predetermined rate, and cannot be changed by any central authority. In the case of Bitcoin, there are about 15 million Bitcoins currently in circulation, with the ultimate number eventually reaching 21 million. This creates concerns about the deflationary aspect of the currency, due to its limited supply in absolute numbers.

Bitcoin was initially popular in part because its (perceived) anonymity enabled trade in illegal goods. On 2 October 2013, the US government shut down the largest website facilitating such trades ${ }^{6}$. Despite this, Bitcoin prices continued to climb for a few months afterwards. Overall, Bitcoin experienced massive fluctuations in value, in part due to speculation, security problems, and general uncertainty as to how the industry would develop.

4 We do not develop a formal model to test for network effects in cryptocurrency markets. Except in rare exceptions, data to estimate such models are typically not available. In our case, the relevant data are not available.

See Section 7

In the process, about $1.5 \%$ of all Bitcoins in circulation at the time were seized by the FBI. 
By the end of 2013, virtually all cryptocurrencies were based on the Bitcoin protocol. They provided alternatives to Bitcoin —often aiming to fix Bitcoin's shortcomings—and therefore are called altcoins. All non-Bitcoin cryptocurrencies in our data are altcoins.

One of the oldest altcoins was Litecoin, created in 2011. The main driving force behind its introduction was the frustration with the complexity of cryptographic tools used in Bitcoin, which promoted the use of powerful specialized hardware in the network. Further, transactions in Litecoin are confirmed in the system in a quarter of the time needed for Bitcoin.

In 2013, Feathercoin further improved on all these dimensions by further changing cryptographic tools, increasing the total number of coins and decreasing the time to confirm transactions. Unfortunately, these changes failed to fix the problem of specialized hardware and deflationary concerns. Peercoin, introduced in 2012, approached the deflationary concerns more effectively by allowing a steady continuous increase in the number of coins in the system ${ }^{7}$. But Peercoin had the same problem with cryptographic complexity as the original Bitcoin system. Novacoin, established in 2013, further improved on Peercoin, Peercoin and Novacoin also employed a different incentive system in the process of validation of transactions, which decreased the need for specialized equipment.

Altogether, by 2014 there were several hundred cryptocurrencies traded in the market ${ }^{8}$. Most of them provided no improvement over Bitcoin, and they used Bitcoin's open-source protocol. This surge in entry into the cryptocurrency market was probably due to the fact that on the one hand the entry is relatively costless, and on the other hand the founders of coins have made significant profits: even the coin with the 34th largest market capitalization had a value of more than one million dollars in February 2014 [7].

Despite the qualitative improvements introduced by other currencies, Bitcoin managed to hold and even increase its leading position in the markets. This is especially interesting because-while it is easy to create a new altcoin with changes in Bitcoin's protocol—it is very difficult to change the Bitcoin protocol itself: changes have to be done by consensus among loosely connected Bitcoin developers [8].

\section{Mining Cryptocurrencies}

Although this paper does not focus on the technical aspects of the supply of cryptocurrencies, we briefly wanted to summarize how the process occurs. Mining is an important aspect of the Bitcoin "institutional" structure. Since there is no central authority, and hence no central record-keeping, Bitcoin solves the key problems of controlling the supply of new bitcoins and verifying transactions via a "mining" process. Although there are some exceptions, most cryptocurrencies work in a similar manner.

In the process of mining, the 'miners' collect posted transactions into a block. They compete with each other in order to add their block of transactions to the blockchain (the ledger of Bitcoin transactions). In order to succeed, a miner needs to be the first one to solve a difficult factorization problem involving prime numbers. Although it is difficult to solve the problem, it is easy to verify that a proposed solution is correct. The difficulty of the problems is automatically adjusted so that a new problem is solved on average every $10 \mathrm{~min}$. The first miner to solve the problem attaches his or her block of transactions and earns the prize in the form of the new bitcoins. Having a powerful computer increases chances of finding the solution earlier than other miners.

In 2009, miners used standard home computers. By 2011, they discovered computer graphic cards could perform the calculation faster. The continuing competition for faster mining calculations created an arms race. A whole industry of super computers has been created with the sole purpose of mining Bitcoins and Bitcoin mining equipment has become a specialist market. It is no longer worthwhile to mine Bitcoin on a standard home computer.

7 The target of $1 \%$ of annual increase perpetually, although at the earlier stage the increase in supply is larger.

8 For a more detailed description of cryptocurrencies see, e.g., [6]. 


\section{Related Literature}

Bitcoin only recently became a subject of research in economics. The topic has been of interest for longer in computer science. A small number of theoretical papers written by computer scientists address incentives. Eyal and Sirer (2013) [9] show that mining is not incentive-compatible and that the so-called "selfish mining" can lead to higher revenue for miners who collude against others. Babaioff et al. (2012) [10] argue that the current Bitcoin protocols do not provide an incentive for nodes to broadcast transactions. This is problematic, since the system is based on the assumption that there is such an incentive. Christin (2013) [11] examines the anonymous online marketplace in cryptocurrencies. Böhme (2013) [12] examines what can be learned from Bitcoin regarding Internet protocol adoption.

There is some work on Bitcoin in legal journals as well, but there is very little in the economics literature. One of the few exceptions is the [13] European Central Bank's (2012) report on virtual currencies. Using two examples, Bitcoin and Linden Dollars, the report focuses on the impact of digital currencies on the use of fiat money. Gans and Halaburda (2015) [14] analyze the economics of private digital currencies, but they explicitly focus on currencies issued by platforms like Facebook or Amazon (that retain full control), and not decentralized currencies like Bitcoin. Dwyer (2014) [15] provides institutional details about digital currency developments. Yermack (2013) [16] analyzes changes in Bitcoin price against fiat currencies and concludes that its volatility undermines its usefulness as currency. Moore and Christin (2013) [17] empirically examine Bitcoin exchange risk. Using Bitcoin traffic at Wikipedia, Glaser et al. (2014) [18] examine whether user interest in cryptocurrencies is due to interest in a ew investment asset or in the currencies themselves. Their results suggest that most of the interest is due to the asset aspect. Bohme et al. (2015) [19] overviews economic forces behind costs and benefits of using Bitcoin. Catalini and Tucker (2016) [20] use Bitcoin experiment to look for forces driving patterns of technology diffusion. None of those papers considers competition between cryptocurrencies.

\section{Data}

Our aim is to analyze whether there are dynamics consistent with network effects in the early development of the market. We do so by examining the changes over time in exchange rates among cryptocurrencies in the nascent cryptocurrency market ${ }^{9}$.

\subsection{Choice of Exchange}

In our analysis, we use data from the BTC-e exchange. This exchange, like other cryptocurrency exchanges, operates as a matching platform. That is, users do not trade with the exchange. Rather, they announce limit orders to buy and sell, and the exchange matches buyers and sellers when conditions of both the buyer and the seller are met.

We use BTC-e because it is an important exchange and because BTC-e has allowed for trading in several currency pairs for a relatively long time. Bitstamp and Bitfinex are the other important largest exchanges, but they only traded the most popular cryptocurrencies. For example, Bitstamp traded only in Bitcoin, while Bitfinex traded only in Bitocin and Litecoin. In terms of market share by exchange, in February 2014 (the middle of the period for which we have data), the three major exchanges were BTC-e (30 percent market share), Bitstamp (28 percent market share), and Bitfinex (26 percent market share). Together these three exchanges had 84 percent of the market ${ }^{10}$. As noted, of these three leaders, only BTC-e traded other currencies besides Bitcoin and Litecoin.

9 We use the terms "exchange rates" and "prices" interchangeably.

10 This excludes the very volatile Chinese exchanges; like Bitstamp and Bitfinex they only permitted trading in Bitcoin and Litecoin. 


\subsection{Currencies Used in the Analysis}

In the analysis, we use the seven cryptocurrencies that have been traded on BTC-e since 2 May 2013 ${ }^{11}$. They are Bitcoin (BTC), Litecoin (LTC), Peercoin (PPC), Namecoin (NMC), Feathercoin (FTC), Novacoin (NVC) and Terracoin (TRC).

These currencies are attractive to analyze for several reasons. First, they include the top three cryptocurrencies (Bitcoin, Litecoin, and Peercoin) in terms of market capitalization on 13 January $2014^{12}$.

Bitcoin and Litecoin, the top two cryptocurrencies, were fairly stable in terms of their market capitalization over the time for which we have data. Bitcoin accounted for approximately $90 \%$ of the total capitalization in cryptocurrencies for the period for which we have data, while Litecoin accounted for approximately $5 \%$. No other cryptocurrency accounted for more than $1 \%$.

BTC-e also trades Namecoin, which ranked fifth among cryptocurrencies in terms of market capitalization on 13 January $2014^{13}$. Hence it was natural to include this "top tier" currency as well.

The currencies traded at BTC-e also include three "second tier" currencies: Feathercoin, Novacoin, and Terracoin. In order to broaden our data, we decided to include these currencies as well. As of 13 January 2014, Feathercoin was 12th, Novacoin 14th and Terracoin 23rd in terms of market capitalization $^{14}$.

\subsection{Variables Employed in the Empirical Analysis}

We employ daily price (i.e., exchange rate) data in the analysis. The source for our pricing data is [7]. The site collects and aggregates the visible data (using API, application programming interface) for multiple exchanges. Historical data on this site were publicly available until 1 July 2014.

Hence, our data set runs from from 2 May 2013 to 1 July 2014. We began the data set in early May 2013 in order to include other currencies in addition to Bitcoin and Litecoin.

We use the "closing rate", as our daily price since this is the one exchange rate that [7] provides. From our discussions with the manager of [7], the closing rate is the exchange rate at midnight GMT. Some currencies are traded more than others, but the top four currencies (BTC, LTC, PPC and NMC) in our data set were traded on a daily basis for the period we analyze ${ }^{15}$.

We include the trading pairs that were traded throughout our sample period. Specifically, while Bitcoin and Litecoin were traded directly for USD, this was not the case for other cryptocurrencies ${ }^{16}$. All the cryptocurrencies we use in the analysis were traded against Bitcoin. In summary, our "price" data consists of following exchange rates:

$$
p_{t}\left(\frac{\mathrm{USD}}{\mathrm{BTC}}\right), p_{t}\left(\frac{\mathrm{USD}}{\mathrm{LTC}}\right) \text {, and } p_{t}\left(\frac{\mathrm{BTC}}{\text { altcoin }}\right), \text { for altcoin }=\mathrm{PPC}, \mathrm{NMC}, \mathrm{FTC}, \mathrm{NVC}, \mathrm{TRC}
$$

for $t$ daily between 2 May 2013 and 1 July 2014.

We also include daily data on the volume of trade between BTC and the USD. This is because we want to allow for the possibility that BTC volume effected exchange rates for the other cryptocurrencies. The source for these data is again [7].

11 Terracoin started trading on BTC-e on 2 May 2013.

12 Market capitalization data are available on many websites. We used [21].

13 The 4th highest ranked currency on that date was MasterCoin, which was not traded at BTC-e.

14 In February 2016, Bitcoin had the highest market capitalization, Litecoin was second, Peercoin was eighth, Namecoin was 16th, Novacoin was 44th, Feathercoin was 78th, and Terracoin completely disappeared.

15 For a very small number of days data for a particular trading pair or a whole exchange is missing. Such cases occurred because either the API of the exchange or cryptocoincharts.info was not working properly. For this reason we are missing data on three dates: 26 January, 16 and 17 March 2014.

16 Some of the other cryptocurrencies started trading directly for USD later in our time frame, but in order to be consistent, we have not included these data in the analysis. 
Finally, at the end of the analysis, we introduce data from Google Trends in order to include a proxy for the general interest in cryptocurrencies. We describe the Google Trends data in detail in Section 6 when we employ that data.

\section{Analysis}

We analyze how the prices of the currencies were changing over time between May 2013 and July 2014. We are particularly interested in how these changes relate one to another.

Specifically, we focus here on two potentially opposing forces present in this market:

(1) a reinforcement effect due to network effects

(2) a substitution effect due to competition

The reinforcement effect is the result of the network effects present in the currency adoption process: As Bitcoin becomes more popular, more people would believe that it will win the winner-take-all race against other cryptocurrencies. With this expectation, the demand will further increase.

The substitution effect is the result of either higher quality alternatives or speculative dynamics. The speculative dynamics arise when cryptocurrencies are treated as financial assets. In such a case, when Bitcoin becomes more popular and more expensive, people fear it may be overvalued (or too volatile) and look for alternative cryptocurrency investments ${ }^{17}$.

As Figure 1 shows, and as many authors pointed out, ${ }^{18}$ Bitcoin's price has been quite volatile throughout its history. The total supply of Bitcoin is governed by an algorithm that does not depend on prices, so there cannot be more Bitcoins created in response to a price increase (much like stocks in the stock market, at least in the short term). Therefore, a change in price indicates a change in the market's overall expectations of Bitcoin's future value and its risk. That is, changes in the price of Bitcoin indicate varied interest in the cryptocurrency and possibly changing economic forces affecting this interest. Importantly, this reasoning implies that prices are the appropriate variable to employ in our analysis. Prices should not only reflect other variables that market participants may observe (e.g., the transactions recorded in Bitcoin's blockchain) but also reflect the expectations of anything that may influence Bitcoin's value in the future, for example current and expected future strength of the network effects. This feature is particularly helpful since such dimensions may be difficult for an econometrician to capture.

One of these economic forces affecting the interest in Bitcoin is competition between cryptocurrencies ${ }^{19}$. If the prices of altcoins are increasing as the price of Bitcoin is increasing, it would indicate a substitution effect between Bitcoin and other cryptocurrencies. If, however, the price of one of the cryptocurrencies increased while others' prices were decreasing, that would indicate a reinforcement effect, and would suggest winner-take-all dynamics in favor of this cryptocurrency.

The earliest theoretical results on network effects (e.g., Katz and Shapiro 1985) predict that network effects favor the first mover. There is no room for competition. Since Bitcoin is the oldest cryptocurrency, introduction of altcoins would always be unsuccessful-in the light of the earliest theories, what we should see in the data is Bitcoin's domination. The reinforcement effect in favor of Bitcoin and against newly established altcoin would be immediate.

17 There is a disagreement about what is driving the demand for cryptocurrencies-whether people buy them due to their potential as currency, or they buy them for speculative purpose, i.e., as a financial asset. This is not the focus of our paper. Yermack (2013) [16] and Glaser et al. (2014) [18] examine this issue.

18 See, e.g., Yermack (2013).

19 Most other cryptocurrencies, and all cryptocurrencies analyzed here, have the same feature of automatic supply as Bitcoin. A cryptocurrency's supply does not respond to the changing price of the cryptocurrency. 


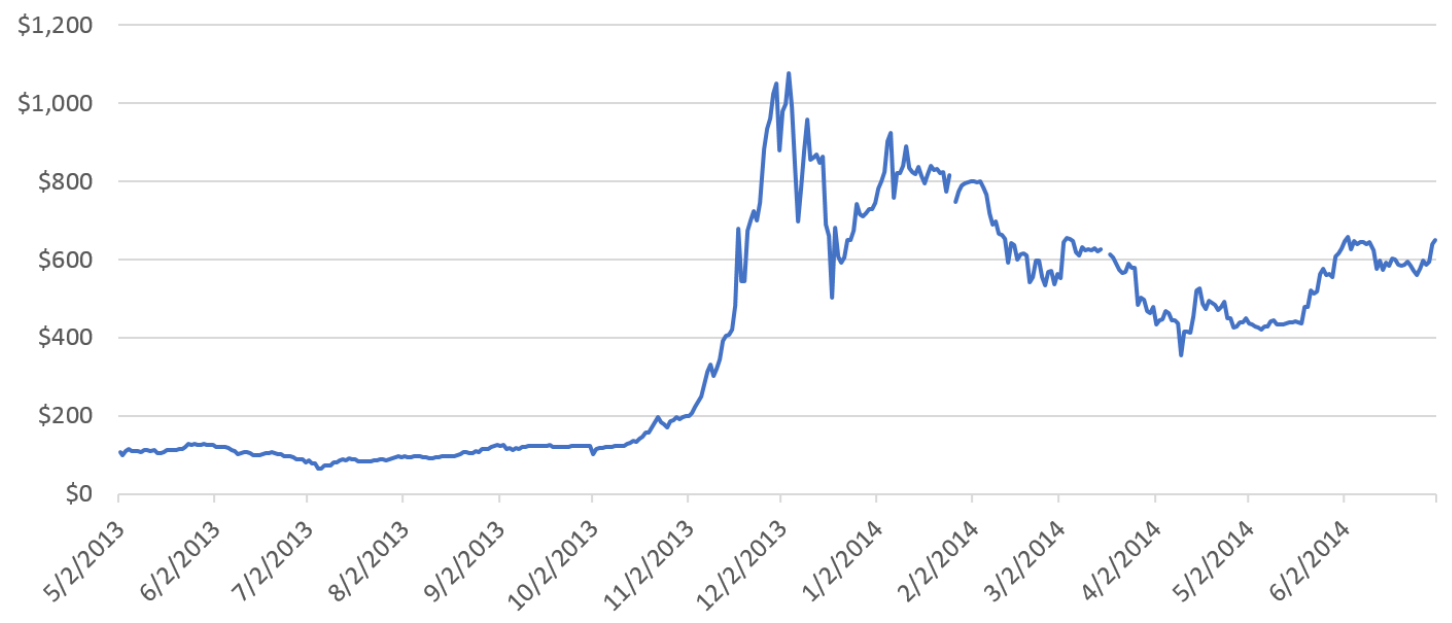

Figure 1. Price of Bitcoin over time.

However, even in the earlier literature there is a debate whether a high quality newcomer can overcome network effects and the first mover advantage (e.g., [3,4]). Theoretical results predict that this could happen, but this is not guaranteed even for sufficiently high quality newcomers (e.g., [22,23]).

More recent literature on platform competition-reviewed for example in Rysman (2009) [24] - argues that under some circumstances competing networks may coexist despite the presence of network effects. This may happen when users have different needs and when differentiated network appeals to different types of users (for example, Cennamo and Santalo (2013) [25] discuss differentiated video game platforms). In such a case, after the introduction of alternatives viably targeting each niche we should observe a sustained substitution effect, as such alternatives become popular and dominant in their own niche. To the best of our knowledge, there are no papers that empirically document how such platform competition develops dynamically and how the interplay of the reinforcement and the substitution effects changes over time.

\subsection{Relation between Bitcoin and Litecoin}

We start by looking at the relation between Bitcoin (BTC) and Litecoin (LTC), the cryptocurrency that was the second most popular throughout our sample, as measured by market capitalization. Figure 2 shows that price movements of Litecoin and Bitcoin have some common patterns, but are not perfectly correlated. Because of a large discrepancy in the magnitude of these prices, in Figure 2 we divide Bitcoin's price by 100 to improve exposition ${ }^{20}$.

When we look at the rolling-window price correlation (Figure 3), we can see that there are large differences over time. From the beginning of our sample until late October there is a large volatility in correlation. The correlation takes both large positive and large negative values. In contrast, from late October until end of April, the correlation looks quite stable at large positive values. Toward the end of our sample, from early May 2014, we see a start of a declining trend in the correlations.

To assess the dynamics of changes, we separately analyze the three periods:

period 1, from 2 May 2013 to 22 October 2013;

period 2, from 23 October 2013 to 30 April 2014;

period 3, from 1 May 2014 to 1 July 2014.

20 For complete descriptive statistics see Table in the Appendix. 


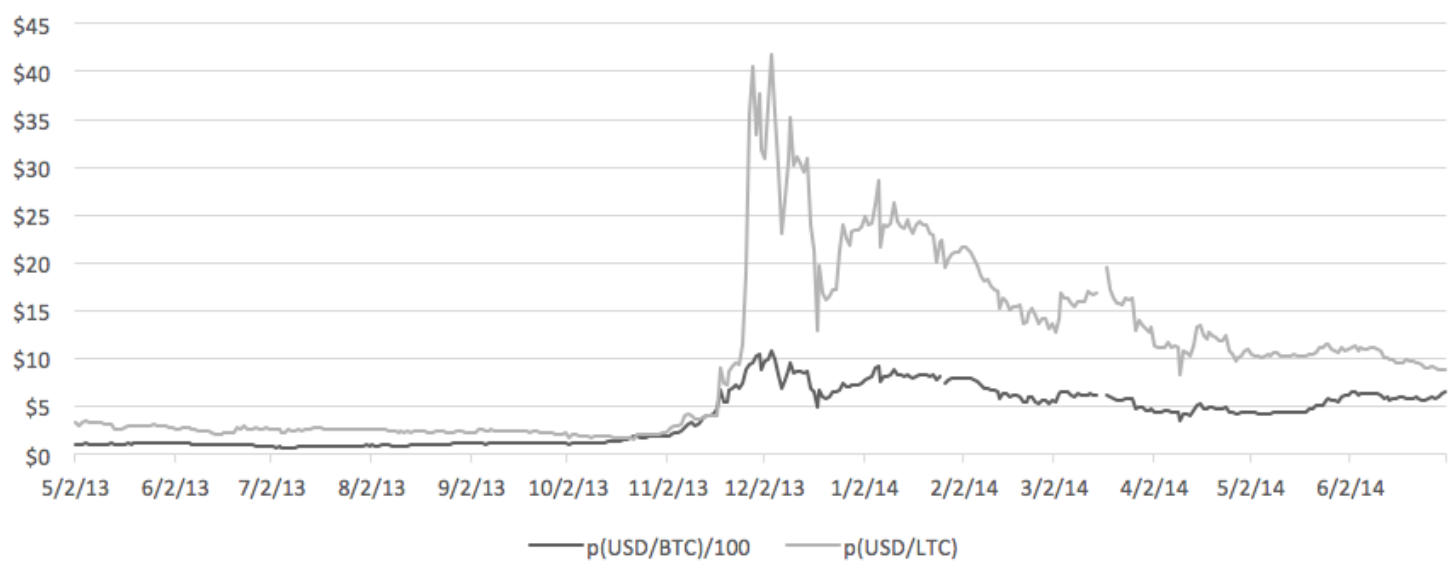

Figure 2. Prices of Litecoin and Bitcoin (Bitcoin's price divided by 100).

1
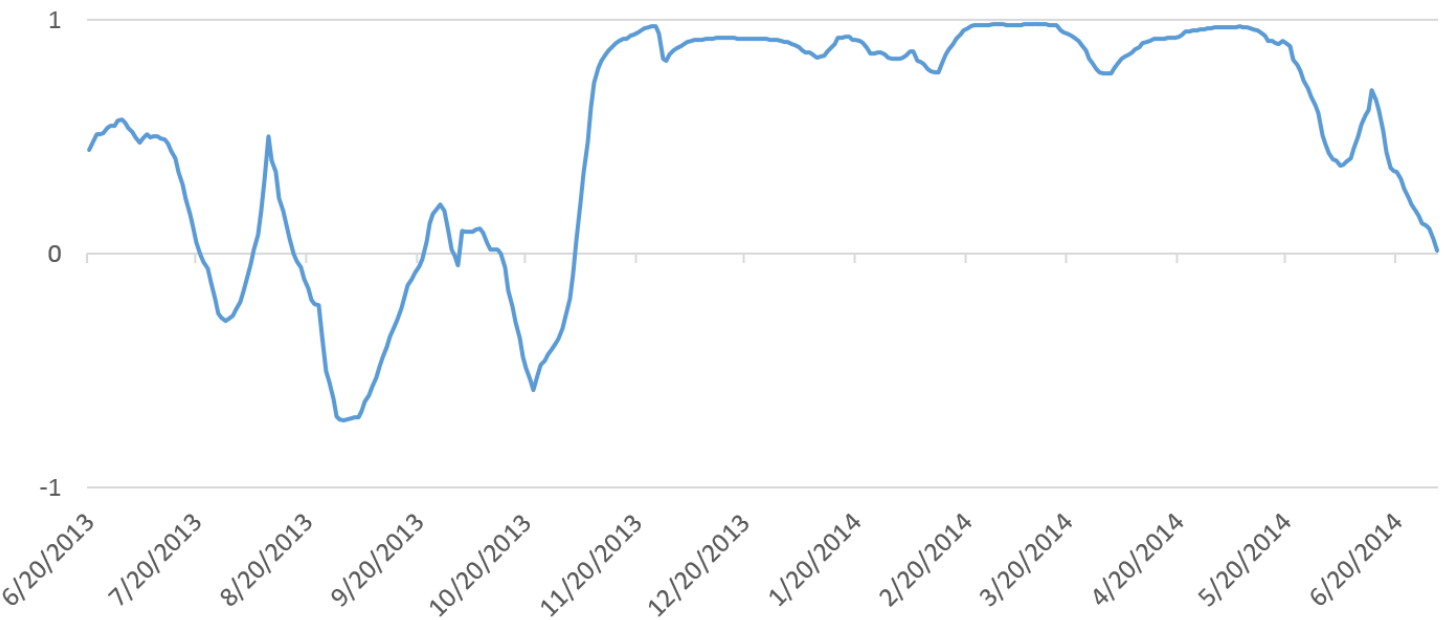

Figure 3. 50-day rolling-window price correlations between Litecoin and Bitcoin.

The price of Bitcoin also behaves somewhat differently in these three periods. Casual observation of Bitcoin prices in Figure 1 indicates that during the May to late October period (period 1) Bitcoin traded within a relatively narrow range of low prices (from \$65/BTC to \$185/BTC). In the period from late October 2013 to the end of April 2014 (period 2), the volatility increased greatly and Bitcoin's prices ranged from $\$ 171 / \mathrm{BTC}$ to $\$ 1076 / \mathrm{BTC} .^{21}$ Bitcoin rises continuously through December 2013, and then begins falling, reaching a low point of slightly more than $\$ 400$ at the end of this period. In May 2014, Bitcoin's price recovers from the turbulent fall and starts steadily climb, reaching $\$ 650$ on 1 July 2014, when our data ends (period 3$)^{22}$.

As noted earlier, there were a number of events in the first half of October that could explain the late October change. On 2 October 2013, US law enforcement raided and shut down Silk Road, a website trading in illegal substances, and using Bitcoin to facilitate anonymity of transactions. In mid-October, Chinese Internet giant Baidu started accepting Bitcoin, which increased Bitcoin's

21 The Cyprus banking crisis ended in March 2013 with the international bailout by the Eurogroup, European Commission (EC), European Central Bank (ECB) and International Monetary Fund (IMF). Our data starts in May 2013. Hence, the Cyprus banking crisis in which the Cypriot government temporarily suspended convertibility of deposits is not the cause of the rise in the price of Bitcoin.

22 See the descriptive statistics in Table in the Appendix. 
popularity in China ${ }^{23}$. It is not clear, however, what caused the May 2014 change in the trend. It may be worth a separate investigation, but this is beyond the scope of our paper.

In periods 1 and 3 the correlation between Bitcoin and Litecoin is small and negative $(-0.32$ and -0.03 , respectively), which could indicate a mild reinforcement effect-Litecoin giving way to Bitcoin. In period 2, however, the correlation is strongly positive, 0.93 , pointing toward substitution effect.

\subsection{Other Cryptocurrencies}

To get a richer picture of the dynamics in this market we also turn to other cryptocurrencies in our sample: Peercoin, Namecoin, Feathercoin, Novacoin, and Terracoin. They were not traded directly for USD at the beginning of our sample, although some started trading directly for USD later in our sample. They were, however, traded for Bitcoin throughout our sample period. Therefore, to get their value in USD, we multiply their value in Bitcoins with the price of Bitcoin $^{24}$ :

$$
p_{t}\left(\frac{\mathrm{USD}}{\text { altcoin }}\right)=p_{t}\left(\frac{\mathrm{USD}}{\mathrm{BTC}}\right) \cdot p_{t}\left(\frac{\mathrm{BTC}}{\text { altcoin }}\right), \text { for altcoin }=\text { PPC, NMC, FTC, NVC, TRC. }
$$

Figure 4 shows all the prices in one graph. As before, for ease of exposition, we plot the Bitcoin's price divided by 100 . We can see that there is some co-movement, especially around the time when Bitcoin's price spikes. When we look at the rolling-window correlations between Bitcoin's price and each of the altcoin's prices (Figure 5), we see a similar pattern as in Litecoin's rolling-window correlation with Bitcoin. There is a large variability in correlations in the first period, including instances of large positive and large negative correlations. In the second period, correlations are all strong and positive. And in the third period there is a clear trend where correlations fall, some of them reaching large negative values.

Figure 5 shows the rolling-window correlations of prices of individual cryptocurrencies with the price of Bitcoin. Table 1 provides additional detail by showing correlations between the different altcoins, within each period. We can see an interesting pattern in how the three periods differ.

We noted earlier that in the first period Litecoin is weakly negatively correlated with Bitcoin, which could indicate a mild reinforcement effects. When we look at the relation between Bitcoin and other cryptocurrencies, and between the altcoins themselves in the first period, this effect is no longer visible. The correlations are in most cases small, sometimes positive, sometimes negative. Neither the substitution nor the reinforcement effect is apparently dominating.

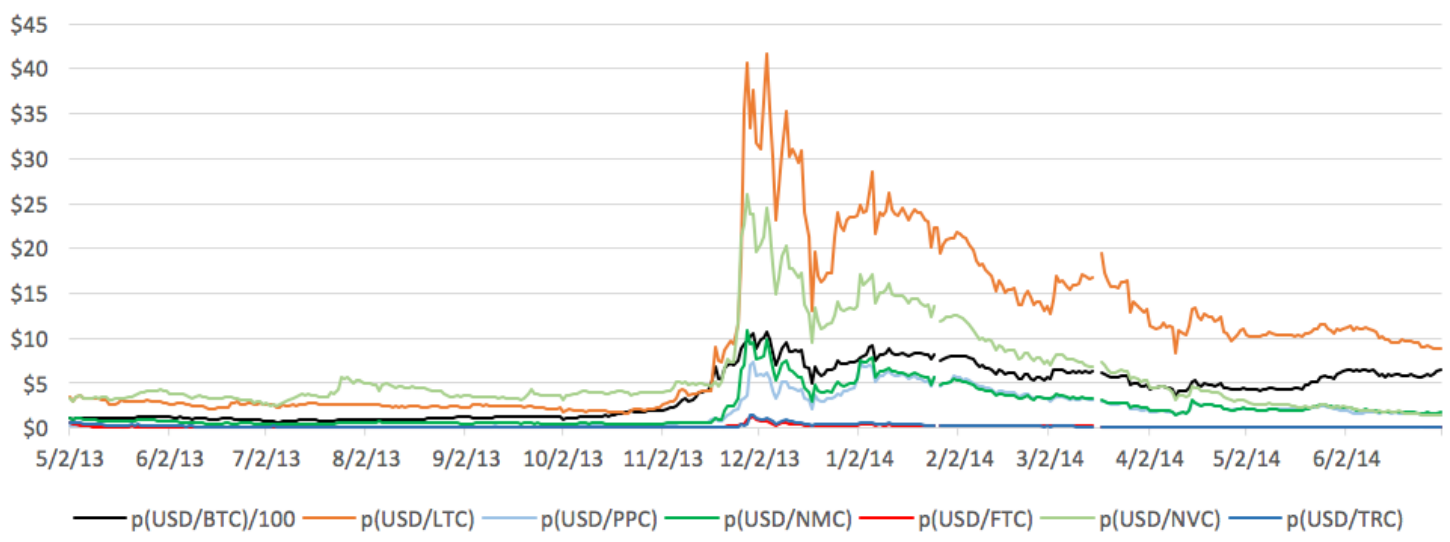

Figure 4. Prices of all cryptocurrencies in the sample (Bitcoin's price divided by 100).

23 See, e.g., Halaburda and Sarvary (2016).

24 We do not need to do so for Litecoin, as it was trading directly for USD throughout our sample. 


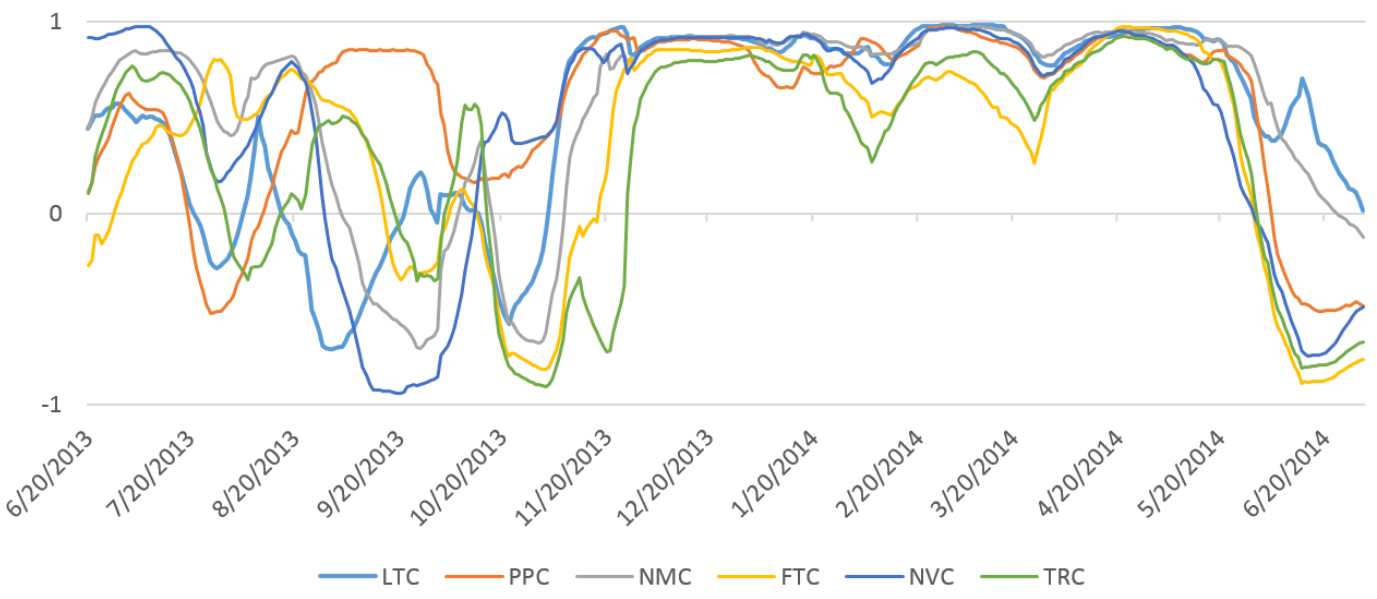

Figure 5. Fifty-day rolling window price correlations between each altcoin and Bitcoin.

Table 1. Correlations between cryptocurrencies' prices, by period.

\begin{tabular}{|c|c|c|c|c|c|c|c|}
\hline \multicolumn{8}{|c|}{ PERIOD 1} \\
\hline & $p\left(\frac{\mathrm{USD}}{\mathrm{BTC}}\right)$ & $p\left(\frac{\mathrm{USD}}{\mathrm{LTC}}\right)$ & $p\left(\frac{\mathrm{USD}}{\text { PPC }}\right)$ & $p\left(\frac{\mathrm{USD}}{\mathrm{NMC}}\right)$ & $p\left(\frac{\mathrm{USD}}{\mathrm{FTC}}\right)$ & $p\left(\frac{\text { USD }}{\text { NVC }}\right)$ & $p\left(\frac{\mathrm{USD}}{\mathrm{TRC}}\right)$ \\
\hline$p\left(\frac{\mathrm{USD}}{\mathrm{BTC}}\right)$ & 1 & & & & & & \\
\hline$p\left(\frac{U S D}{\text { LTC }}\right)$ & -0.32 & 1 & & & & & \\
\hline$p\left(\frac{\mathrm{USD}}{\mathrm{PPC}}\right)$ & 0.57 & -0.29 & 1 & & & & \\
\hline$p\left(\frac{\text { USD }}{\text { NMC }}\right)$ & 0.15 & 0.74 & 0.19 & 1 & & & \\
\hline$p\left(\frac{\mathrm{USSD}}{\mathrm{FTC}}\right)$ & 0.037 & 0.42 & 0.23 & 0.63 & 1 & & \\
\hline$p\left(\frac{\operatorname{USD}}{\mathrm{NVC}}\right)$ & 0.058 & -0.11 & -0.0087 & 0.072 & -0.024 & 1 & \\
\hline$p\left(\frac{\text { USD }}{\text { TRC }}\right)$ & 0.090 & 0.71 & 0.24 & 0.91 & 0.739 & -0.17 & 1 \\
\hline \multicolumn{8}{|c|}{ PERIOD 2} \\
\hline$p\left(\frac{\mathrm{USD}}{\mathrm{BTC}}\right)$ & 1 & & & & & & \\
\hline$p\left(\frac{U S D}{L T C}\right)$ & 0.93 & 1 & & & & & \\
\hline$p\left(\frac{U S D}{P P C}\right)$ & 0.89 & 0.87 & 1 & & & & \\
\hline$p\left(\frac{\mathrm{USD}}{\mathrm{NMC}}\right)$ & 0.94 & 0.97 & 0.92 & 1 & & & \\
\hline$p\left(\frac{U S D}{\text { FTC }}\right)$ & 0.80 & 0.86 & 0.72 & 0.89 & 1 & & \\
\hline$p\left(\frac{\mathrm{USD}}{\mathrm{NVC}}\right)$ & 0.89 & 0.92 & 0.80 & 0.95 & 0.91 & 1 & \\
\hline$p\left(\frac{U S D}{T R C}\right)$ & 0.77 & 0.85 & 0.74 & 0.87 & 0.94 & 0.90 & 1 \\
\hline \multicolumn{8}{|c|}{ PERIOD 3} \\
\hline$p\left(\frac{\mathrm{USD}}{\mathrm{BTC}}\right)$ & 1 & & & & & & \\
\hline$p\left(\frac{U S D}{\text { LTC }}\right)$ & -0.028 & 1 & & & & & \\
\hline$p\left(\frac{\mathrm{USD}}{\mathrm{PPC}}\right)$ & -0.56 & 0.72 & 1 & & & & \\
\hline$p\left(\frac{U S D}{\text { NMC }}\right)$ & -0.12 & 0.839 & 0.85 & 1 & & & \\
\hline$p\left(\frac{U S D}{\text { FTC }}\right)$ & -0.85 & 0.42 & 0.82 & 0.53 & 1 & & \\
\hline$p\left(\frac{\mathrm{USD}}{\mathrm{NVC}}\right)$ & -0.70 & 0.65 & 0.88 & 0.67 & 0.92 & 1 & \\
\hline$p\left(\frac{\text { USSD }}{\text { TRC }}\right)$ & -0.79 & 0.46 & 0.82 & 0.57 & 0.96 & 0.90 & 1 \\
\hline
\end{tabular}

In the second period, the correlations are universally positive and large (above 0.7), which suggest a strong substitution effect among different cryptocurrencies is dominating, without any one winner.

In the third period, the correlation between Bitcoin and altcoins are negative, although varying in strength. Bitcoin's correlation with Litecoin and Namecoin are negative but weak, while correlation with other altcoins are strongly negative. Correlations between altcoins, however, are positive and strong. This suggests that the reinforcement effect in favor of Bitcoin is dominating, while all of the other cryptocurrencies are positively correlated in the "losing" group. 
The pattern of Bitcoin "winning it all" in the market emerges only in period 3. We do not observe indicators of such future dynamics in periods 1 and 2.

\subsection{Percentage Changes in Prices}

When analyzing assets including currencies, researchers and market analysts are typically more interested in returns (i.e., percentage changes) than in price levels. First, returns may be easier to work with if the price level series is nonstationary ${ }^{25}$. More importantly, changes in prices (returns) will directly capture changes in the strength of the network effects of different cryptocurrencies. This happens because the attractiveness of the platform increases when its network effects become stronger (e.g., the seminar paper of Katz and Shapiro, 1985). As that happens, the value of being able to participate in the platform increases relative to other goods (i.e., the dollar price of each bitcoin goes up), resulting in a positive return. This increase may in fact directly reflect the growth in the network. If more consumers want to use Bitcoin, they need to acquire units of the cryptocurrency, increasing the demand. Since supply of the cryptocurrency is fixed, prices must adjust, with returns reflecting the direction and the magnitude of shift in demand. Moreover, one can compare the rate of return for two different cryptocurrencies and assess the relative improvements to the network effects on one versus the other: for example, we would expect larger returns for the cryptocurrency that attracts a larger proportion of the market ${ }^{26}$.

Depending on whether the substitution or the reinforcement effect dominates, an increase in Bitcoin's popularity may increase or decrease altcoins' values. Increased popularity is reflected in a higher price of Bitcoin. Since increased popularity of Bitcoin could also potentially be reflected in volume of Bitcoin to USD trade, we include change in Bitcoin's volume in the regressions ${ }^{27}$.

We run regressions of returns $r_{t}$ (altcoin) on $r_{t}(\mathrm{BTC})$ and percentage change in volume, $\% \Delta$ vol $_{t}(\mathrm{BTC})$, for altcoin $=\mathrm{LTC}, \mathrm{PPC}, \mathrm{NMC}, \mathrm{FTC}, \mathrm{TRC}$, where

$$
r_{t}(\text { altcoin })=\frac{p_{t}\left(\frac{\mathrm{USD}}{\text { altcoin }}\right)-p_{t-1}\left(\frac{\mathrm{USD}}{\text { altcoin }}\right)}{p_{t-1}\left(\frac{\mathrm{USD}}{\text { altcoin }}\right)}
$$

and percentage change for Bitcoin's price and volume are calculated similarly. Table 2 reports the results.

The regression results in Table 2 are consistent with the second period being a period where the substitution effect dominates, while periods 1 and 3 are periods where the reinforcement effect dominates.

Note first that, on average, the price of Bitcoin appreciated versus the USD in each of the three periods we consider here in the sense that the price of Bitcoin was higher at the end of each of the three periods for which we have data ${ }^{28}$. Thus, the new information or change in beliefs that affected exchange rates was, on average, positive for Bitcoin. That information was likely partly driven by news about the overall cryptocurrency market (the attractiveness of cryptcurrencies overall) and partly about information specific to a particular cryptocurrency (e.g., Bitcoin's competitive advantage versus other cryptocurrencies).

25 And that is indeed the case with our data.

26 While altcoins may have a different supply schedule than Bitcoin, some even allowing for indefinite increases, this difference does not affect returns. This is because every altcoin's supply schedule is completely predetermined. That schedule known in advance to investors, and in efficient markets quantities known in advance do not affect prices or returns. In other words, changes in supply are no news to investors, are impounded into prices ex ante, and there is no reaction at the time when they do occur. Thus, the differences in returns are driven by differences in cryptocurrencies' attractiveness.

27 In regressions that relate various cryptocurrencies to both Bitcoin and other altcoins, the latter show no clear pattern, generally with no signifance, changing signs for different cryptocurrencies and for different samples, etc. In contrast, Bitcoin has a statistically and economically important impact, as discussed below.

28 See Table in the Appendix. This is true despite the huge fall in the price of Bitcoin from its peak in December 2013. 
Table 2. Regressions of altcoins' returns on percentage change in Bitcoin's price and volume, period by period.

\begin{tabular}{|c|c|c|c|c|c|c|}
\hline Dept. Variables & $\begin{array}{c}\text { (1) } \\
r(\mathrm{LTC})\end{array}$ & $\begin{array}{c}(2) \\
r(\mathrm{PPC})\end{array}$ & $\begin{array}{c}\text { (3) } \\
r(\mathrm{NMC})\end{array}$ & $\begin{array}{c}\text { (4) } \\
r(\text { FTC })\end{array}$ & $\begin{array}{c}(5) \\
r(\mathrm{NVC})\end{array}$ & $\begin{array}{c}\text { (6) } \\
r(\mathrm{TRC})\end{array}$ \\
\hline \multicolumn{7}{|l|}{ PERIOD 1} \\
\hline$r(\mathrm{BTC})$ & $0.57^{* * *}(7.79)$ & $0.42^{* * *}(3.27)$ & $0.67^{* * *}(5.56)$ & $0.40^{* *}(2.13)$ & $0.74^{* * *}(8.33)$ & $0.52^{* * *}(3.42)$ \\
\hline$\% \Delta \operatorname{vol}(\mathrm{BTC})$ & $-0.01^{* *}(-2.56)$ & $-0.0089(-1.25)$ & $-0.0077(-1.16)$ & $0.00(0.00)$ & $-0.0082 *(-1.67)$ & $-0.012(-1.37)$ \\
\hline constant & $-0.0078(-2.59)$ & $-0.0018(-0.35)$ & $-0.0079(-1.60)$ & $-0.0093(-1.22)$ & $-0.0023(-0.62)$ & $-0.012(-1.85)$ \\
\hline observations & 174 & 174 & 174 & 173 & 174 & 174 \\
\hline adj R-squared & 0.29 & 0.06 & 0.16 & 0.02 & 0.30 & 0.07 \\
\hline \multicolumn{7}{|l|}{ PERIOD 2} \\
\hline$r(\mathrm{BTC})$ & $1.48^{* * *}(16.49)$ & $1.33^{* * *}(15.84)$ & $1.65^{* * *}(15.62)$ & $1.28^{* * *}(11.81)$ & $0.94^{* * *}(12.81)$ & $1.35^{* * *}(5.48)$ \\
\hline$\% \Delta \operatorname{vol}(\mathrm{BTC})$ & $0.0042(0.95)$ & $-0.00053(-0.13)$ & $0.0023(0.45)$ & $0.0033(0.62)$ & $-0.00018(-0.05)$ & $0.0012(0.10)$ \\
\hline constant & $0.0082(1.12)$ & $0.0096(1.39)$ & $0.0084(0.97)$ & $0.0048(0.55)$ & $-0.0034(-0.67)$ & $0.014(0.71)$ \\
\hline observations & 185 & 185 & 185 & 185 & 185 & 185 \\
\hline adj R-squared & 0.59 & 0.58 & 0.57 & 0.43 & 0.47 & 0.13 \\
\hline \multicolumn{7}{|l|}{ PERIOD 3} \\
\hline$r(\mathrm{BTC})$ & $0.48^{* * *}(6.73)$ & $0.77^{* * *}(5.32)$ & $0.80^{* * *}(7.31)$ & $0.76^{* *}(2.51)$ & $0.66^{* * *}(4.30)$ & $1.72^{* * *}(4.12)$ \\
\hline$\% \Delta \operatorname{vol}(\mathrm{BTC})$ & $0.00072(0.21)$ & $-0.0065(-0.92)$ & $0.012 *(2.19)$ & $0.016(1.06)$ & $0.018^{* *}(2.34)$ & $-0.011(-0.53)$ \\
\hline constant & $-0.0063(-2.67)$ & $-0.0079(-1.60)$ & $-0.0058(-1.61)$ & $-0.010(-1.00)$ & $-0.013(-2.58)$ & $-0.018(-1.31)$ \\
\hline observations & 62 & 62 & 62 & 62 & 62 & 62 \\
\hline adj R-squared & 0.42 & 0.16 & 0.50 & 0.50 & 0.28 & 0.19 \\
\hline
\end{tabular}

t-Statistics in parentheses. ${ }^{* * *} p<0.01,{ }^{* *} p<0.05,{ }^{*} p<0.1$; we do not denote significance for the constant terms. 
Since the coefficients estimated in Table 2 are positive, the first channel likely dominates across the overall sample. This is consistent with returns to cryptocurrencies going up in USD overall throughout this period. The first channel should, on average, affect all cryptocurrencies similarly. But the second channel will impact them in opposing ways (good news specifically for Bitcoin is bad news for the competing altcoins). Then, the differences between estimates can be interpreted as being informative about the relative strength of the competitive pressures over time.

Because the estimated coefficients in periods 1 and 3 are generally lower than one, this suggests that the first channel was partly offset by the second channel. This offsetting pressure reflected the reinforcement effect, which was beneficial for Bitcoin in periods 1 and 3. In contrast, almost all estimated coefficients are greater than one in period 2. Indeed, in period 2, with the exception of Novacoin and Terracoin, 95\% confidence intervals for the estimated coefficient associated with the variable $r$ (BTC) do not include one in the confidence interval, that is, the lower bound for the $95 \%$ confidence interval for that parameter is above one for Litecoin, Peercoin, Namecoin, and Feathercoin.

There was good news overall for the cryptocurrency market in this period. This news was amplified for altcoins other than Bitcoin. Prices of all four "first tier" cryptocurrencies in our sample went up significantly between the beginning and the end of period $2{ }^{29}$. While the price of Bitcoin increased by $143 \%$ in this period, the prices of Litecoin, Peercoin, and Namecoin all rose by over $400 \%$. This amplification is consistent with Bitcoin losing some competitive advantage against other cryptocurrencies, perhaps because it was viewed as less likely to dominate the entire cryptocurrency market ${ }^{30}$.

Adjusted $\mathrm{R}^{2} \mathrm{~s}$ also give us insights into how the relation between the cryptocurrencies was changing between the periods. In the first period, the estimated coefficients indicate a reinforcement effect in favor of Bitcoin. But the effect does not play a large role in the dynamics of cryptocurrency prices, as the changes in Bitcoin's returns explain only a very small portion of variation in altcoin's returns. The changes in altcoins' prices in this period may have been more influenced by their own development communities.

The relation between Bitcoin and altcoins plays a larger role in the second and third periods. The changes in Bitcoin's returns explain much more of altrcoins' variation-at first via substitution effect in period 2, and then via reinforcement effect in period 3. The estimates suggest that up to $60 \%$ of altcoin's variability in period 2 and up to about half of variability in period 3 can be explained by what was happening to Bitcoin in these periods.

\subsection{Robustness Analysis}

As we noted, BTC-e was the only major exchange that allowed trading in several cryptocurrencies. As a robustness check, we examined data from Bitstamp, which is one of the major cryptocurrency exchanges. As noted earlier, Bitstamp only allows trade between Bitcoin and USD. Hence, we compared Bitcoin's prices in UDS for BTC-e and Bitstamp for all of our three periods. Correlations between the prices on the two exchanges were $0.9968,0.9957$, and 0.9974 in periods one two and three, respectively. This suggests that Bitcoin to USD price movements were quite similar across exchanges.

We conducted additional robustness analysis by breaking down the data into 60-day periods-and the main results in Table 1 continue to hold. Namely, in the 60-day periods associated with our "first period", there is (similar to our results in Table 1) no special pattern in the correlation rates among

29 See Table in the Appendix.

30 Note that that the percentage change in volume is not significant in the majority of the regressions. 
the cryptocurrencies. In the 60-day periods associated with our second period, the correlations are universally positive and large, again similar to the results for the full second period reported in Table $1^{31}$.

As a final robustness check we also investigated potential interactions between cryptocurrencies. In our analysis above, we focused on the relationship between Bitcoin on the one hand and altcoins on the other. We chose this approach because Bitcoin is the incumbent in the cryptocurrency ecosystem. However, there might be potential interactions between individual altcoins as well. We test for such effects by repeating our baseline regressions by this time relating returns to one altcoin to returns of both Bitcoin and all remaining altcoins. This analysis indicates no patterns in the signs or significance of interactions between individual altcoins. We report the results of this analysis in Table in the Appendix for the most popular altcoin: Litecoin. The relationship between Litecoin and Bitcoin is very similar to that we report in Table 2, while the relationship between Litecoin and other altcoins tends to be insignificant and has no consistent sign; where it happens to be significant for one period, it loses significance in another, etc. We conclude that the interactions between individual cryptocurrencies are largely limited to those between Bitcoin and individual altcoins.

\section{Accounting for General Interest in Cryptocurrencies}

Results in the previous sections suggest that the relative strength of the substitution and reinforcement effects is driven by the general interest in cryptocurrencies as opposed to interest in a particular cryptocurrency, e.g., Bitcoin. To further disentangle the relationship between how (i) Bitcoin and (ii) general interest in cryptocurrencies affected altcoins, we include a proxy for the general interest in cryptocurrencies using Google Trends. To capture this interest, we use the search intensity for the two general terms usually associated with cryptocurrencies, "cryptocurrency" and "virtual currency", provided by Google Trends ${ }^{32}$. We present the pattern in these search terms in Figure 6. The figure shows steady interest in cryptocurrencies until about the beginning of period 2, when the interest abruptly increases and remains high until about the beginning of period 3 , when interest gradually wanes.

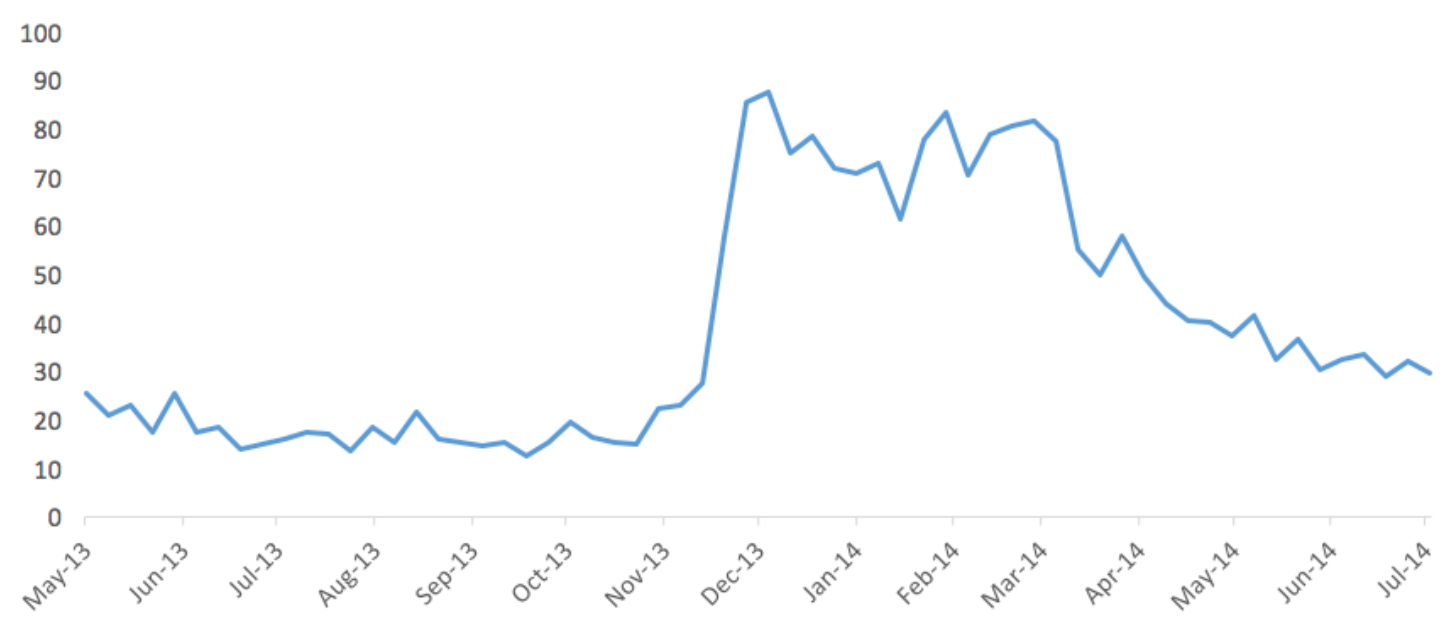

Figure 6. Average number of Google searches related to cryptocurrencies.

Google trend data is only available weekly, so we recalculate the returns on Bitcoin and the altcoins to match that frequency. This reduces our overall sample size to 60 observations. Given the

31 Our third period has only 62 observations; hence the final 60-day period has virtually identical results.

32 Google Trends does not provide an absolute number of searches. Rather, it provides a relative search intensity on a weekly asis. The week with the largest number of searches is benchmarked at 100, and the number of searches in all other weeks are scaled relative to this benchmark. 
limited number of observations, we no longer further divide the data into the three periods; in fact, we are aiming to explain some of the differences between the periods using our proxy variable for the general interest in cryptocurrencies. We next estimate the regressions, as reported in Table 3.

We begin with the basic regressions (from Table 2) that simply relate the percentage changes in the price of each altcoin to USD in the percentage change in Bitcoin's price over the same week and the percentage change in volume. The results in Table 3 support those we discussed earlier: we find strong positive correlations between Bitcoin and altcoins; for Litcoin in regression (1), Peercoin in regression (3), etc. The estimated coefficients all exceed 1, which suggests that the particularly turbulent period 2 drives the overall regression results.

We next add two additional explanatory variables: the overall Google search intensity (Google) and the interaction between Bitcoin returns and the Google search intensity $\left(r(\mathrm{BTC})^{*} \text { Google }\right)^{33}$. To the extent that Google Trends reflect the overall interest in cryptocurrencies, we expect both the Google Trends variable and the interaction term to capture the substitution effect. This suggests that the coefficients on the Google Trends term and the interaction term should both be positive. This is indeed what we find in Table 3.

Our results are three-fold. Firstly, Table 3 shows that the number of Google searches in a given week is positively correlated with returns on each individual altcoin, and for five out of six the relationship is statistically significant at the $10 \%$ level.

Secondly, The effect of the interaction term is even stronger. Returns on Bitcoin are more important for the altcoins when they are accompanied by more search activity and hence stronger interest in cryptocurrencies overall. Indeed, the estimated coefficient on the interaction term is positive and statistically significant in all six regressions ${ }^{34}$.

Finally and strikingly, controlling for the overall interest in cryptocurrencies, we find that the relationship between Bitcoin and altcoin returns is actually negative or there is no effect. The sign of the estimate is negative for each of the six altcoins we consider here, although only for three is the estimated coefficient significant at the $10 \%$ level. These results are consistent with the reinforcement effect, and again suggest that-while the general interest in cryptocurrencies was driving substitution effect in period 2-the reinforcement effect was more important in periods 1 and 3, which were less buoyed by the overall interest in cryptocurrencies ${ }^{35}$.

\section{Further Discussion}

Our data ends in 1 July 2014 due to the technical limitations we discussed earlier. But the reinforcement-effect pattern from the third period is also visible when we look at how those cryptocurrencies are doing at the time of writing, compared to the beginning of the third period. As Table 4 shows, Bitcoin has maintained its value since 1 May 2014 (beginning of the third period) while other cryptocurrencies have fallen sharply. Some of them by more than 90 percent. Currencies like Feathercoin and Terracoin, while still listed on some exchanges, are all but gone from the market.

33 The correlation between Bitcoin returns and Google search intensity is -0.071 . Also note that the LHS variables in the regressions in Table 3 (the returns of altcoins) do not cause either (i) Bitcoin returns or (ii) affect Google searches. Hence, there is no endogeneity problem and OLS is appropriate here.

34 Table 3 shows that the additional two variables in the regression-Google Trends and the interaction term-lead to a very large increase in adjusted R-squared for all six regressions.

35 Similar to the results in Table 2, percent changes in the volume of Bitcoin are insignificant in the regressions in Table 3. 
Table 3. Regressions on returns accounting for interest in cryptocurrencies as measured by Google searches.

\begin{tabular}{|c|c|c|c|c|c|c|c|c|c|c|c|c|}
\hline Dept. Variables & $\begin{array}{c}\text { (1) } \\
r(\mathrm{LTC})\end{array}$ & $\begin{array}{c}(2) \\
r(\mathrm{LTC})\end{array}$ & $\begin{array}{c}(3) \\
r(\mathrm{PPC})\end{array}$ & $\begin{array}{c}(4) \\
r(\mathrm{PPC})\end{array}$ & $\begin{array}{c}(5) \\
r(\mathrm{NMC})\end{array}$ & $\begin{array}{c}(6) \\
r(\mathrm{NMC})\end{array}$ & $\begin{array}{c}(7) \\
r(\text { FTC })\end{array}$ & $\begin{array}{c}(8) \\
r(\mathrm{FTC})\end{array}$ & $\begin{array}{c}(9) \\
r(\mathrm{NVC})\end{array}$ & $\begin{array}{c}(10) \\
r(\mathrm{NVC})\end{array}$ & $\begin{array}{c}\text { (11) } \\
r(\mathrm{TRC})\end{array}$ & $\begin{array}{c}(12) \\
r(\mathrm{TRC})\end{array}$ \\
\hline$r(\mathrm{BTC})$ & $\begin{array}{c}1.59 * * * \\
(6.80)\end{array}$ & $\begin{array}{c}-0.43 \\
(-1.17)\end{array}$ & $\begin{array}{c}1.70 * * * \\
(5.41)\end{array}$ & $\begin{array}{l}-0.94 * \\
(-1.81)\end{array}$ & $\begin{array}{c}2.06^{* * *} \\
(7.07)\end{array}$ & $\begin{array}{c}-0.41 \\
(-0.90)\end{array}$ & $\begin{array}{c}1.95^{* * *} \\
(5.47)\end{array}$ & $\begin{array}{l}-0.95 * \\
(-1.61)\end{array}$ & $\begin{array}{c}1.12 * * * \\
(6.03)\end{array}$ & $\begin{array}{c}-0.20 \\
(-0.60)\end{array}$ & $\begin{array}{c}3.215^{* * *} \\
(3.42)\end{array}$ & $\begin{array}{l}-3.75^{* *} \\
(-2.31)\end{array}$ \\
\hline$r(\mathrm{BTC}) *$ Google & & $\begin{array}{c}0.04^{* * *} \\
(6.40)\end{array}$ & & $\begin{array}{c}0.06^{* * *} \\
(5.87)\end{array}$ & & $\begin{array}{c}0.05^{* * *} \\
(6.42)\end{array}$ & & $\begin{array}{c}0.06^{* * *} \\
(5.70)\end{array}$ & & $\begin{array}{c}0.03^{* * *} \\
(4.49)\end{array}$ & & $\begin{array}{c}0.15^{* * *} \\
(4.97)\end{array}$ \\
\hline Google & & $\begin{array}{c}0.003^{* *} \\
(2.44)\end{array}$ & & $\begin{array}{l}0.003^{*} \\
(1.72)\end{array}$ & & $\begin{array}{c}0.004^{* *} \\
(2.43)\end{array}$ & & $\begin{array}{c}0.004^{*} \\
(2.08)\end{array}$ & & $\begin{array}{l}0.001 \\
(1.18)\end{array}$ & & $\begin{array}{c}0.012 * \\
(2.04)\end{array}$ \\
\hline$\% \Delta$ vol BTC & $\begin{array}{l}-0.002 \\
(-1.28) \\
\end{array}$ & $\begin{array}{c}-0.01 \\
(-0.81)\end{array}$ & $\begin{array}{c}-0.02 \\
(-0.93) \\
\end{array}$ & $\begin{array}{r}-0.004 \\
(-0.32) \\
\end{array}$ & $\begin{array}{c}-0.02 \\
(-1.16) \\
\end{array}$ & $\begin{array}{c}-0.01 \\
(-0.66)\end{array}$ & $\begin{array}{c}-0.03 \\
(-1.53)\end{array}$ & $\begin{array}{c}-0.02 \\
(-1.13) \\
\end{array}$ & $\begin{array}{c}-0.02 \\
(-1.66)\end{array}$ & $\begin{array}{c}-0.01 \\
(-1.25)\end{array}$ & $\begin{array}{c}-0.06 \\
(-1.25)\end{array}$ & $\begin{array}{c}-0.03 \\
(-0.82)\end{array}$ \\
\hline constant & $\begin{array}{c}0.01 \\
(0.28) \\
\end{array}$ & $\begin{array}{c}-0.09 \\
(-1.49) \\
\end{array}$ & $\begin{array}{c}0.04 \\
(0.63) \\
\end{array}$ & $\begin{array}{c}-0.06 \\
(-0.69) \\
\end{array}$ & $\begin{array}{c}0.01 \\
(0.15) \\
\end{array}$ & $\begin{array}{c}-0.12 \\
(-1.60) \\
\end{array}$ & $\begin{array}{l}0.004 \\
(0.06) \\
\end{array}$ & $\begin{array}{c}-0.14 \\
(-1.40) \\
\end{array}$ & $\begin{array}{c}-0.01 \\
(-0.31) \\
\end{array}$ & $\begin{array}{c}-0.05 \\
(-0.96) \\
\end{array}$ & $\begin{array}{c}0.08 \\
(0.42) \\
\end{array}$ & $\begin{array}{c}-0.32 \\
(-1.16) \\
\end{array}$ \\
\hline observations & 60 & 60 & 60 & 60 & 60 & 60 & 60 & 60 & 60 & 60 & 60 & 60 \\
\hline adj. R-squared & 0.45 & 0.72 & 0.34 & 0.62 & 0.47 & 0.72 & 0.35 & 0.63 & 0.40 & 0.58 & 0.18 & 0.48 \\
\hline
\end{tabular}

$\mathrm{t}$-Statistics in parentheses. ${ }^{* * *} p<0.01{ }^{* *} p<0.05,{ }^{*} p<0.1$. 
Table 4. Change in cryptocurrencies' prices between 1 May 2014 and 29 February 2016. Data for 29 February 2016 from [21].

\begin{tabular}{|c|c|c|c|}
\hline & 1 May 2014 & 29 February 2016 & $\%$ Change \\
\hline$p_{t}\left(\frac{\mathrm{USD}}{\mathrm{BTC}}\right)$ & 448.99 & 437.16 & -2.4 \\
\hline$p_{t}\left(\frac{\mathrm{USD}}{\mathrm{LTC}}\right)$ & 11.02 & 3.45 & -68.7 \\
\hline$p_{t}\left(\frac{\mathrm{USD}}{\mathrm{PPC}}\right)$ & 2.21 & 0.46 & -79.2 \\
\hline$p_{t}\left(\frac{\mathrm{USD}}{\mathrm{NMC}}\right)$ & 2.21 & 0.42 & -81.0 \\
\hline$p_{t}\left(\frac{\mathrm{USD}}{\mathrm{FTC}}\right)$ & 0.09 & 0.0058 & -93.6 \\
\hline$p_{t}\left(\frac{\mathrm{USD}}{\mathrm{NVC}}\right)$ & 3.14 & 0.98 & -68.8 \\
\hline$p_{t}\left(\frac{\mathrm{USS} D}{\mathrm{TRC}}\right)$ & 0.09 & 0.0031 & -96.6 \\
\hline
\end{tabular}

Additionally, in February 2016 Bitcoin accounts for 93.5\% of the total market capitalization, while Litecoin accounts for $2.5 \%$. Hence, at the time of writing Bitcoin accounts for a larger percentage of market capitalization than it did for the period for which we have detailed data.

Hence, despite its shortcomings, Bitcoin seems to have emerged—at least at this stage-as the clear winner. There may be higher quality alternatives, but, in the end, the network effects led to Bitcoin being the only winner.

As our analysis shows, there was no easy way to predict such an outcome from the early dynamics of the market. After observing the trend in period 2, one may have been tempted to extrapolate continuation of this trend into the future. But such prediction would have been incorrect. Nonetheless, we often encounter such predictions in the world of business and technology. Some of them even enter the popular history as examples of stark misestimations-like Thomas Watson, president of IBM, in 1943 stating "I think there is a world market for maybe five computers" 36 .

Our analysis shows how the temptation to make such predictions may arise. But making a prediction that "the market entered a persistent co-evolution of different cryptocurrencies" at the end of period 2 would have been similarly incorrect as that of Thomas Watson's. This is why it is even more intriguing that we do not know what events brought on the May 2014 change. With a change so clear as this one, we often look for one event that would drive it. We leave this for future research.

Acknowledgments: For helpful comments and suggestions we thank Jonathan Chiu, Geoffrey Dunbar, Brad Greenwood, Ben Fung, Rod Garratt, Raffaella Giacomini, Scott Hendry, Michael Kummer, Lukasz Pomorski, Miguel Molico, Gerald Stuber, Russel Wong, participants at NET Institute Conference 2015, International IO Conference 2015, Searle Center Conference on Internet Search and Innovation at Northwestern University 2015, Platform Strategy Research Symposium 2015, and seminars at the Bank of Israel, University of Toronto, Goteborg University, New York University and at the Board of Governors of the Federal Reserve System. We thank Yaniv Friedensohn and Chris Henry for invaluable research assistance. We gratefully acknowledge financial support from the Pinhas Sapir Center for Development (sapir.tau.ac.il) and from the NET Institute (www.netinst.org).

Author Contributions: Two authors contributed equally to this work.

Conflicts of Interest: The authors declare no conflict of interest.

36 See, e.g., PC World, The 7 Worst Tech Predictions of All Time [26]. 


\section{Appendix}

Table A1. Cryptocurrency prices at threshold dates. Data for 29 February 2016 from [21].

\begin{tabular}{|c|c|c|c|c|c|}
\hline & $\begin{array}{c}\text { Start of } \\
\text { Period 1: } \\
2 \text { May 2013 }\end{array}$ & $\begin{array}{l}\text { End of } \\
\text { Period 1: } \\
22 \text { October } 2013\end{array}$ & $\begin{array}{c}\text { End of } \\
\text { Period 2: } \\
30 \text { April 2014 }\end{array}$ & $\begin{array}{c}\text { End of } \\
\text { Period 3: } \\
\text { 1 July 2014 }\end{array}$ & $\begin{array}{l}\text { February 2016: } \\
\text { 29 February } 2016\end{array}$ \\
\hline$p_{t}\left(\frac{\mathrm{USD}}{\mathrm{BTC}}\right)$ & 106.8 & 184.6 & 438.4 & 650 & 437.2 \\
\hline$p_{t}(\mathrm{USD})$ & 3.41 & 1.62 & 10.86 & 8.78 & 3.45 \\
\hline$p_{t}\left(\frac{\mathrm{USD}}{\mathrm{PPC}}\right)$ & 0.28 & 0.28 & 2.17 & 1.40 & 0.46 \\
\hline$p_{t}\left(\frac{U S D}{N M C}\right)$ & 1.09 & 0.40 & 2.14 & 1.77 & 0.42 \\
\hline$p_{t}\left(\frac{U S D}{F T C}\right)$ & 0.54 & 0.063 & 0.088 & 0.045 & 0.0058 \\
\hline$p_{t}\left(\frac{\mathrm{USD}}{\mathrm{NVC}}\right)$ & 3.35 & 3.07 & 3.14 & 1.39 & 0.98 \\
\hline$p_{t}\left(\frac{\mathrm{USD}}{\mathrm{TRC}}\right)$ & 0.54 & 0.089 & 0.088 & 0.045 & 0.0031 \\
\hline
\end{tabular}

Table A2. Descriptive Statistics of Cryptocurrencies' Prices (in USD) and Bitcoin's trading volume (in BTC), by period.

\begin{tabular}{|c|c|c|c|c|c|}
\hline & \# of obs. & mean & std. dev. & $\min$ & $\max$ \\
\hline \multicolumn{6}{|l|}{ PERIOD 1} \\
\hline$p_{t}\left(\frac{\mathrm{USD}}{\mathrm{BTC}}\right)$ & 174 & 109 & 18 & 66 & 185 \\
\hline$p_{t}\left(\frac{\mathrm{PSD}}{\mathrm{UTC}}\right)$ & 174 & 2.53 & 0.37 & 1.62 & 3.56 \\
\hline$p_{t}\left(\frac{\mathrm{USD}}{\mathrm{PPC}}\right)$ & 174 & 0.18 & 0.073 & 0.11 & 0.47 \\
\hline$p_{t}\left(\frac{\mathrm{USD}}{\mathrm{NMC}}\right)$ & 174 & 0.59 & 0.15 & 0.39 & 1.12 \\
\hline$p_{t}\left(\frac{\mathrm{USD}}{\mathrm{FTC}}\right)$ & 174 & 0.12 & 0.060 & 0.060 & 0.54 \\
\hline$p_{t}\left(\frac{\mathrm{USD}}{\mathrm{NVC}}\right)$ & 174 & 3.77 & 0.61 & 2.44 & 5.58 \\
\hline$p_{t}\left(\frac{\mathrm{USS} \mathrm{D}}{\mathrm{TRC}}\right)$ & 174 & 0.19 & 0.094 & 0.085 & 0.58 \\
\hline $\operatorname{vol}(\mathrm{BTC})$ & 174 & 4960 & 4034 & 1075 & 28,193 \\
\hline \multicolumn{6}{|l|}{ PERIOD 2} \\
\hline$p_{t}\left(\frac{\mathrm{USD}}{\mathrm{BTC}}\right)$ & 187 & 613 & 205 & 171 & 1076 \\
\hline$p_{t}\left(\frac{\mathrm{PSD}}{\mathrm{LTC}}\right)$ & 187 & 16.51 & 8.53 & 2.03 & 41.69 \\
\hline$p_{t}\left(\frac{\mathrm{USD}}{\mathrm{PPC}}\right)$ & 187 & 3.31 & 1.82 & 0.31 & 7.35 \\
\hline$p_{t}\left(\frac{\mathrm{USD}}{\mathrm{NMC}}\right)$ & 187 & 3.73 & 2.23 & 0.42 & 10.86 \\
\hline$p_{t}\left(\frac{\mathrm{USD}}{\mathrm{FTC}}\right)$ & 187 & 0.25 & 0.18 & 0.068 & 1.21 \\
\hline$p_{t}\left(\frac{\mathrm{USD}}{\mathrm{NVC}}\right)$ & 187 & 9.55 & 5.36 & 3.05 & 26.07 \\
\hline$p_{t}\left(\frac{\mathrm{USD}}{\mathrm{TRC}}\right)$ & 187 & 0.29 & 0.25 & 0.033 & 1.53 \\
\hline $\operatorname{vol}(\mathrm{BTC})$ & 187 & 16,702 & 16,820 & 314 & 129,307 \\
\hline \multicolumn{6}{|l|}{ PERIOD 3} \\
\hline$p_{t}\left(\frac{\mathrm{USD}}{\mathrm{BTC}}\right)$ & 62 & 544 & 82 & 421 & 657 \\
\hline$p_{t}\left(\frac{\mathrm{USD}}{\mathrm{LTC}}\right)$ & 62 & 10.31 & 0.70 & 8.78 & 11.51 \\
\hline$p_{t}\left(\frac{\mathrm{USD}}{\mathrm{PPC}}\right)$ & 62 & 1.89 & 0.28 & 1.38 & 2.42 \\
\hline$p_{t}\left(\frac{\mathrm{USD}}{\mathrm{NMC}}\right)$ & 62 & 2.03 & 0.26 & 1.65 & 2.68 \\
\hline$p_{t}\left(\frac{\mathrm{USD}}{\mathrm{FTC}}\right)$ & 62 & 0.060 & 0.016 & 0.039 & 0.90 \\
\hline$p_{t}\left(\frac{\mathrm{USSD}}{\mathrm{NVC}}\right)$ & 62 & 2.18 & 0.44 & 1.39 & 3.14 \\
\hline$p_{t}\left(\frac{U S D}{T R C}\right)$ & 62 & 0.062 & 0.014 & 0.035 & 0.90 \\
\hline $\operatorname{vol}(\mathrm{BTC})$ & 62 & 6277 & 4026 & 1176 & 17,171 \\
\hline
\end{tabular}


Table A3. Robustness analysis. Regression of Litecoin's returns on returns of other cryptocurrencies and percentage change in Bitcoin's volume, by period.

\begin{tabular}{|c|c|c|c|}
\hline Dept. Variables & $\begin{array}{c}\text { (1) } \\
r(\mathrm{LTC})\end{array}$ & $\begin{array}{c}(2) \\
r(\mathrm{LTC})\end{array}$ & $\begin{array}{c}(3) \\
r(\mathrm{LTC})\end{array}$ \\
\hline$r(\mathrm{BTC})$ & $\begin{array}{c}0.49 * * * \\
(5.07)\end{array}$ & $\begin{array}{c}1.13^{* * *} \\
(6.51)\end{array}$ & $\begin{array}{l}0.26^{* *} \\
(2.62)\end{array}$ \\
\hline$r(\mathrm{PPC})$ & $\begin{array}{c}0.03 \\
(0.66)\end{array}$ & $\begin{array}{c}-0.14 \\
(-1.21)\end{array}$ & $\begin{array}{l}0.14^{*} \\
(1.99)\end{array}$ \\
\hline$r(\mathrm{NMC})$ & $\begin{array}{c}0.13^{* * *} \\
(2.63)\end{array}$ & $\begin{array}{c}0.18^{* *} \\
(2.26)\end{array}$ & $\begin{array}{c}0.09 \\
(1.04)\end{array}$ \\
\hline$r(\mathrm{FTC})$ & $\begin{array}{c}0.04 \\
(1.14)\end{array}$ & $\begin{array}{c}0.12 \\
(1.54)\end{array}$ & $\begin{array}{c}-0.04 \\
(-1.05)\end{array}$ \\
\hline$r(\mathrm{NVC})$ & $\begin{array}{c}0 \\
(-0.07)\end{array}$ & $\begin{array}{l}0.20 * \\
(1.77)\end{array}$ & $\begin{array}{l}0.11^{*} \\
(1.87)\end{array}$ \\
\hline$r(\mathrm{TRC})$ & $\begin{array}{l}0.01 \\
(0.3)\end{array}$ & $\begin{array}{l}-0.08^{*} \\
(-1.91)\end{array}$ & $\begin{array}{c}0.01 \\
(0.49)\end{array}$ \\
\hline$\% \Delta v o l(\mathrm{BTC})$ & $\begin{array}{c}-0.01 \\
(-1.41)\end{array}$ & $\begin{array}{c}0 \\
(0.6)\end{array}$ & $\begin{array}{c}0 \\
(-0.84)\end{array}$ \\
\hline constant & $\begin{array}{c}0 \\
(-0.66)\end{array}$ & $\begin{array}{c}0.01 \\
(0.92)\end{array}$ & $\begin{array}{c}0 \\
(-0.95)\end{array}$ \\
\hline observations & 174 & 185 & 62 \\
\hline R-squared & 0.335 & 0.677 & 0.572 \\
\hline Period & 1 & 2 & 3 \\
\hline
\end{tabular}

\section{References}

1. Katz, M.; Shapiro, C. Network externalities, competition, and compatibility. Am. Econ. Rev. 1985, 75, 424-440.

2. The Opportunities of Alt coins. Available online: https://letstalkbitcoin.com/the-opportunity-of-alt-coins/. UpzXuMRDs-E (accessed on 29 February 2016).

3. David, P.A. Clio and the economics of QWERTY. Am. Econ. Rev. 1985, 75, 332-337.

4. Leibowitz, S.J.; Margolis, S.E. Network externality: An uncommon tragedy. J. Econ. Perspect. 1994, 8, $133-150$.

5. Bitcoin Exchange Mt.Gox Goes Offline Amid Allegations of 350 Million Hack. Available online: http:/ /www.wired.com/2014/02/bitcoins-mt-gox-implodes-2/ (accessed on 29 February 2016).

6. Halaburda, H.; Sarvary, M. Beyond Bitcoin; Palgrave Macmillan: London, UK, 2016.

7. Cryptocoin Charts. Available online: http://www.cryptocoincharts.info/ (accessed on 29 February 2016).

8. A Bitcoin Believer's Crisis of Faith. Available online: http://www.nytimes.com/2016/01/17/business/deal book/the-bitcoin-believer-who-gave-up.html (accessed on 29 February 2016).

9. Majority Is Not Enough: Bitcoin Mining Is Vulnerable. Available online: http://i.cdn.turner.com/ money/2013/images/11/04/btcProc.pdf (accessed on 29 February 2016).

10. On Bitcoin and Red Balloons, Mimeo. Available online: http://dl.acm.org/citation.cfm?id=2229022 (accessed on 29 February 2016).

11. Christin, N. Traveling the silk road: A measurement analysis of a large anonymous online marketplace. In Proceedings of the 22nd International World Wide Web Conference, Rio de Janeiro, Brazil, 13-17 May 2013; pp. 213-224.

12. Böhme, R. Internet protocol adoption: Learning from Bitcoin. In IAB Workshop on Internet Technology Adoption and Transition (ITAT); Internet Architecture Board (IAB): Cambridge, UK, 2013.

13. Virtual Currency Schemes 2012. Available online: http://www.ecb.europa.eu/pub/pdf/other/virtual currencyschemes201210en.pdf (accessed on 29 February 2016).

14. Gans, J.; Halaburda, H. Some economics of private digital currency. In Economic Analysis of the Digital Economy; Goldfarb, A., Greenstein, S., Tucker, C., Eds.; The University of Chicago Press: Chicago, IL, USA, 2015.

15. Dwyer, G. The Economics of Private Digital Currency, Mimeo. Available online: http://brianmlucey.files. wordpress.com/2014/01/gerald-dwyer-economicsdigitalcurrency.pdf (accessed on 29 February 2016). 
16. Yermack, D. Is Bitcoin a Real Currency? NYU Stern School of Business, 2013. Available online: http:/ / papers. ssrn.com/sol3 / papers.cfm?abstract_id=2361599 (accessed on 29 February 2016).

17. Moore, T.; Christin, N. Beware the middleman: Empirical analysis of bitcoin-exchange risk. Financ. Cryptogr. Data Secur. 2013, 7859, 25-33.

18. Glaser, F.; Zimmermann, K.; Haferkorn, M.; Weber, M.; Siering, M. Bitcoin-Asset or Currency? Revealing Users' Hidden Intentions, 2014. Available online: http://papers.ssrn.com/sol3/papers. cfm?abstract_id=2425247 (accessed on 29 February 2016).

19. Böhme, R.; Christin, N.; Edelman, B.; Moore, T. Bitcoin: Economics, technology, and governance. J. Econ. Perspect. 2015, 29, 213-238.

20. Catalini C.; Tucker, C. Seeding the Technology S-Curve? The Role of Early Adopters in Technology Diffusion; Questrom School of Business, Boston Univesity: Boston, MA, USA, 2016.

21. Crypto-Currency Market Capitalizations. Available online: http://coinmarketcap.com/ (accessed on 29 February 2016).

22. Zhu, F.; Iansiti, M. Entry into platform-based markets. Strateg. Manag. J. 2012, 33, 88-106.

23. Jullien, B.; Halaburda, H.; Yehezkel, Y. Dynamic Competition with Network Externalities: Why History Matters; CEPR Discussion Paper No. DP11205; CEPR: London, UK, 2016.

24. Rysman M. The Economics of Two-Sided Markets. J. Econ. Prespect. 2009, 23, 125-143.

25. Cennamo, C.; Santalo, J. Platform competition: Strategic trade-offs in platform markets. Strateg. Manag. J. 2013, 34, 1331-1350.

26. The 7 Worst Tech Predictions of All Time. Available online: http://www.pcworld.com/article/ 155984/worst_tech_predictions.html (accessed on 29 February 2016).

(C) 2016 by the authors; licensee MDPI, Basel, Switzerland. This article is an open access article distributed under the terms and conditions of the Creative Commons Attribution (CC-BY) license (http:/ / creativecommons.org/licenses/by/4.0/). 